\title{
ANÁLISE DA SUSCEPTIBILIDADE À DESERTIFICAÇÃO EM AMBIENTE DE CAATINGA
}

\author{
ANALYSIS OF SUSCEPTIBILITY TO DESERTIFICATION IN CAATINGA ENVIRONMENT
}

\section{RESUMO}

A susceptibilidade ambiental indica a probabilidade de fragilidade natural em relação à determinadas problemáticas ambientais, como as relacionadas à desertificação. Por este estudo, objetivou-se identificar as áreas susceptíveis à desertificação em ambientes da caatinga, tendo como escala de análise os municípios de Canudos e Jeremoabo, localizados no norte do estado da Bahia. Aplicou-se a lógica fuzzy para a integração de dados físico-ambientais (litologia, solos e variáveis do relevo) e elaboração da modelagem de susceptibilidade. 0 índice topográfico de umidade, declividade, plano e perfil de curvatura do relevo foram extraídos do modelo digital de terreno (MDT) e compuseram as variáveis do relevo. Após a elaboração e análise do cenário ambiental, constatou-se que $13 \%$ do território em estudo correspondem à susceptibilidade severa e a susceptibilidade alta a $15 \%$, e ambas se encontram em relevos ondulados, forteondulados e montanhosos, em ambientes de médio-baixo e baixo índice topográfico de umidade. Nos municípios, destacam-se a susceptibilidade média, a qual é superior a $40 \%$. Os dados oriundos da modelagem demonstram a necessidade de realizar um planejamento eficaz de uso do solo, a fim de evitar ou reduzir os processos de degradação ambiental do bioma caatinga, por meio da adoção de práticas conservacionistas no tocante de combater ações que desencadeiem a erosão acelerada, fator do processo de desertificação.

Palavras-chave: Análise ambiental. Degradação. Erosão. Geotecnologias. Manejo das terras.

\section{ABSTRACT}

Environmental susceptibility indicates the probability of natural fragility concerning certain environmental issues, such as those related to desertification. The aim of this study was to identify areas susceptible to desertification in caatinga environments, based on the analysis of Canudos and Jeremoabo, both located in the northern area of Bahia. Fuzzy logic was applied in order to integrate the physical-environmental data (lithology, soils, and relief variables) and elaborate the susceptibility modeling. The topographic indexes of humidity, declivity, plane and profile of the relief curvature were obtained from the digital elevation model (DEM) and assembled the relief variable. After the composition and analysis of the environmental scenario, we observed that $13 \%$ of the studied territory corresponds to severe susceptibility and $15 \%$ corresponds to high susceptibility. Besides, we verified that both areas located in undulated relief, heavily undulated relief and mountainous relief and are in environments of medium-low and low topographic humidity index. In the cities we investigated, an average susceptibility stands out, which is higher than $40 \%$. The data derived from the modeling shows the need to carry out an effective soil use in order to avoid or reduce environmental degradation processes of the caatinga biome, such as conservation practices to avoid actions that produce accelerated erosion, element of the desertification process.

Keywords: Environmental analysis. Degradation. Erosion. Geotechnologies. Land management.

\author{
Anderson de Jesus Pereira ${ }^{a}$ \\ Israel de Oliveira Junior ${ }^{b}$ \\ Jocimara Souza Britto Lobão a \\ a Universidade Estadual de Feira de \\ Santana (UEFS), Feira de Santana, BA, \\ Brasil \\ b Universidade Federal da Bahia (UFBA), \\ Salvador, BA, Brasil
}

DOI: $10.12957 /$ geouerj.2020.39260

Correpondência: iojjunior@gmail.com

Recebido em: 5 jan. 2019

Revisado em: 24 maio 2020

Aceito em: 27 maio. 2020 


\section{INTRODUÇÃO}

Os solos constituem elementos indispensáveis para a ocorrência da vida na Terra e a sua qualidade determina, de forma significativa, a natureza dos ecossistemas, das plantas e a capacidade da Terra em sustentar a vida animal e dos seres humanos. À medida que alteramos as características superficiais da terra, menos contato direto temos com o solo e perdemos de vista o quanto dependemos dele para a sobrevivência humana e desenvolvimento social.

Os modos de exploração agrícola pressionam o ambiente e geram processos de desequilíbrio ambiental em diversas áreas do planeta (ABDI et al., 2013; BORTOLUZZI et al., 2006; FENG et al., 2015; HAMZA; WALTER, 2005; HARE et al., 1992; KATYAL; VLEK, 2000; OLIVEIRA JUNIOR et al., 2018; QIAN et al., 2017; RÊGO, 2012; SHAH et al., 2017). As consequências do modelo predatório agrícola refletem diretamente nas características dos ecossistemas, onde observam-se perdas da biodiversidade, em função de alterações profundas no habitat, aceleração dos processos erosivos e declínio da fertilidade do solo (HARE et al., 1992; QIAN et al., 2017; SHAH et al., 2017), contribuindo para o processo de degradação, em que, nas terras secas, têm-se na desertificação a face mais perversa.

A problemática da desertificação ganhou relevância mundial nos anos de 1930, quando o fenômeno conhecido como Dust Bowl, no meio-oeste estadunidense, revelou a intensa degradação ambiental, decorrente do desmatamento e intensificação da exploração dos solos por meio da agricultura e pecuária, agravados por forte seca (LEE; GILL, 2015). Nesse momento, houve uma alteração das propriedades físicas, químicas e biológicas dos solos, que são importantes componentes da produtividade agrícola e dos ecossistemas. Por isso, a seleção e a utilização adequada de cada tipo de solo para o desenvolvimento das atividades agropecuárias são de fundamental importância para a manutenção do equilíbrio do sistema ambiental (NASCIMENTO, 2015).

Prevenir e combater a degradação e suas consequências são metas da Convenção das Nações Unidas de Combate à Desertificação (UNCCD) nos países afetados por seca grave e/ou desertificação. O termo é usado quando a degradação torna uma terra produtiva em improdutiva, causada pela ação humana direta a partir do uso da terra para o plantio de monocultura, pastagem sem técnicas de conservação adequadas e o desmatamento descontrolado (UNCCD, 1997). Esses processos intensificam a erosão dos solos, reduzem a chuva e a retenção da umidade no solo, causam um desequilíbrio no sistema terra, água e planta.

Segundo a UNCCD (1997), a desertificação ocorre em áreas de clima árido, semiárido e subúmido seco, a partir da destruição do potencial produtivo da terra. Quando os solos se tornam inférteis é porque a desertificação já se materializou no ambiente, como uma consequência das práticas insustentáveis, aumentando a pobreza, desigualdade e desestruturação social.

Os processos de degradação incluem uma variedade de alterações físicas, químicas e biológicas nas propriedades pedológicas e nos processos edáficos, que conduzem a uma redução da qualidade do solo como recurso (COSTA et al., 2009). A erosão tem sido considerada um dos piores processos de degradação do solo no mundo, além de ser o principal 
processo associado ao abandono da terra e à desertificação (NASCIMENTO, 2015). Os usos das terras secas devem considerar a fragilidade natural dos ecossistemas, para evitar os impactos que geram a desertificação, pois eles possuem um equilíbrio delicado, em especial durante à época das estiagens pluviométricas (HARE et al., 1992).

O bioma caatinga possui uma área de $734.000 \mathrm{~km}^{2}$ (SOUZA et al., 2015) e nele dominam as altas temperaturas atmosféricas, solos poucos intemperizados, escassa capacidade de armazenamento de água no solo, pluviosidade abaixo de $800 \mathrm{~mm}$, chuvas concentradas e torrenciais, ocorrência de seca, evapotranspiração permanentemente alta, pequena produção de fitomassa e predomínio de vegetação estépica (NASCIMENTO, 2015).

A Área Susceptível à Desertificação (ASD) no Brasil caracteriza-se por longos períodos de seca, seguidos por outros curtos de chuvas intensas de enxurradas. Ambos os processos, secas e chuvas torrenciais, costumam provocar significativos prejuízos econômicos, sociais, culturais e ambientais, que tendem a atingir, com maior rigor, a parcela da população menos favorecida economicamente, dessa forma os mais pobres são os mais afetados pela variabilidade climática regional. Pelo exposto, faz-se necessário a identificação de áreas susceptíveis à erosão, pois constitui um indicador ambiental importante no contexto da desertificação.

Na escala mundial, tornou-se consensual a urgência em discutir o problema, para a promoção de medidas de reconhecimento, monitoramento das causas, consequências e da complexa reversão de seus efeitos (ARAÚJO; SOUZA, 2017), pois, como aponta Hare et al. (1992, p. 23), “a desertificação pode alimentar-se a si mesma e tornar-se autoacelerada" e a "degradação pode atingir um limiar para além do qual passa a ser prática e economicamente irreversível", denotando a urgência de práticas preventivas. No estudo sobre o processo de desertificação, o solo é uma variável importante, principalmente pelo aumento da pressão causada pela produção agropecuária, que tem contribuído para gerar e/ou intensificar processos erosivos, degradação dos recursos florestais e perdas de habitats, comuns em áreas desertificadas (ARAÚJO; SOUZA, 2017; HARE et al., 1992; NASCIMENTO, 2015; PEREZ-MARIN et al., 2012).

Geralmente, o processo de degradação inicia-se pela retirada da cobertura vegetal, porque expõe o solo totalmente às intempéries climáticas e torna-o mais suscetível aos diferentes tipos de erosão, devido à estrutura dos solos, declividade do relevo, concentração e torrencialidade das chuvas e pelas técnicas de manejo ambiental. A erosão acelerada ocorre, principalmente, nas áreas de acentuada declividade, de solos arenosos, desprovidas de cobertura vegetal e onde o uso da terra é inadequado (GUERRA et al., 2014; SANTOS et al., 2010). A permanência desses fatores configura um ciclo de pressão-estado-impacto da degradação, que pode evoluir à desertificação.

A susceptibilidade indica a probabilidade de ocorrência de determinadas problemáticas ambientais, como a desertificação, em função das características naturais, a exemplo da litologia, das variáveis do relevo e do solo. Existem solos que são considerados altamente friáveis, como o Neossolo quartzarênico, Neossolo litólico e Vertissolo, de baixa resistência aos fatores erosivos (ARAGÃO et al., 2011; CREPANI et al., 2008, SALOMÃO, 2012). Em relação ao Vertissolo, 
a presença de argilas expansíveis, baixa permeabilidade e alto escoamento superficial hídrico (EMBRAPA, 2006) o tornam susceptível aos processos de erosão diante das chuvas de enxurradas, comuns nos ambientes de caatinga.

Com isso, as ferramentas do sistema de informações geográficas (SIG) possibilitam a integração de informações provenientes de diferentes bases de dados, como a cartografia e imagens orbitais, para mapear, correlacionar e analisar a susceptibilidade dos solos à degradação a partir de inferências das classes, por meio de variáveis que compõem o seu sistema de formação, como a litologia, declividade e clima (MELENDEZ-PASTOR et al., 2010). Assim, por este estudo, objetivou-se analisar a susceptibilidade à desertificação, a partir da elaboração de um modelo ambiental, com a integração de elementos físico-ambientais, no intuito de discutir questões referentes à fragilidade natural de ambientes da caatinga.

\section{ÁREA DE ESTUDO}

A unidade espacial de análise compreende os municípios de Canudos e Jeremoabo, situados no norte do estado da Bahia (Figura 1). Eles integram a Área Susceptível à Desertificação do Brasil e neles há indícios de intensa degradação (LOBÃO; VALE, 2013).

Figura 1. Localização dos municípios de Canudos e Jeremoabo, Bahia - área de estudo

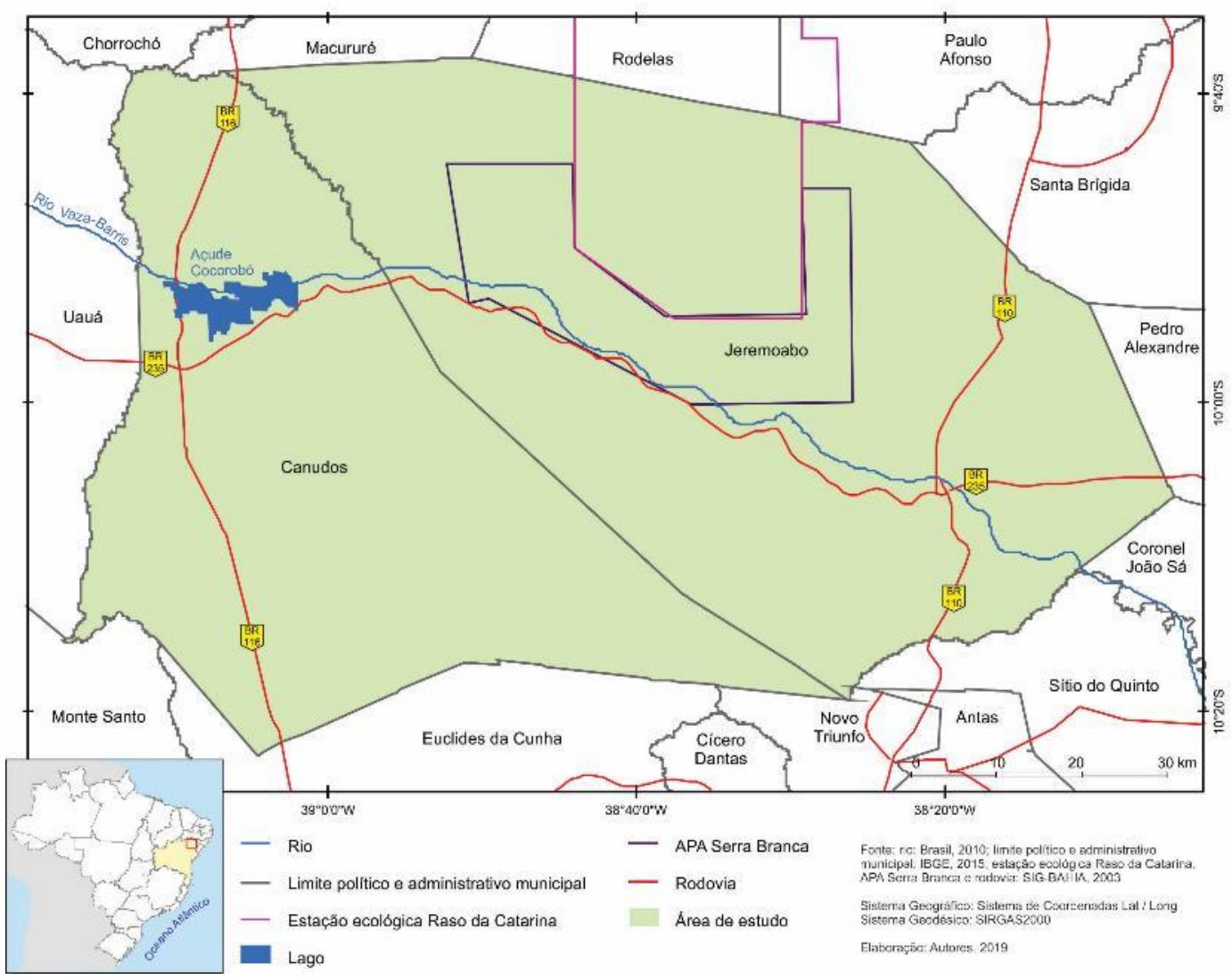


Canudos e Jeremoabo encontram-se sob o domínio do clima tropical semiárido, com médias pluviométricas mensais que oscilam entre $3,6 \mathrm{~mm}$ a $81,7 \mathrm{~mm}$ (Tabela 1). Canudos, especificamente, possui a temperatura média anual de $24,60 \mathrm{C}$, evapotranspiração potencial de $1.328,9 \mathrm{~mm}$ e precipitações pluviométricas em torno de 378,9mm (SEI, 1999) (Tabela 1). No município chove muito pouco e a concentração de chuvas ocorrem entre fevereiro e abril, com um longo período de vazios pluviométricos (Tabela 1).

Tabela 1. Distribuição mensal de variáveis climáticas dos municípios de Canudos e Jeremoabo - Bahia. Fonte: SEI, 1999

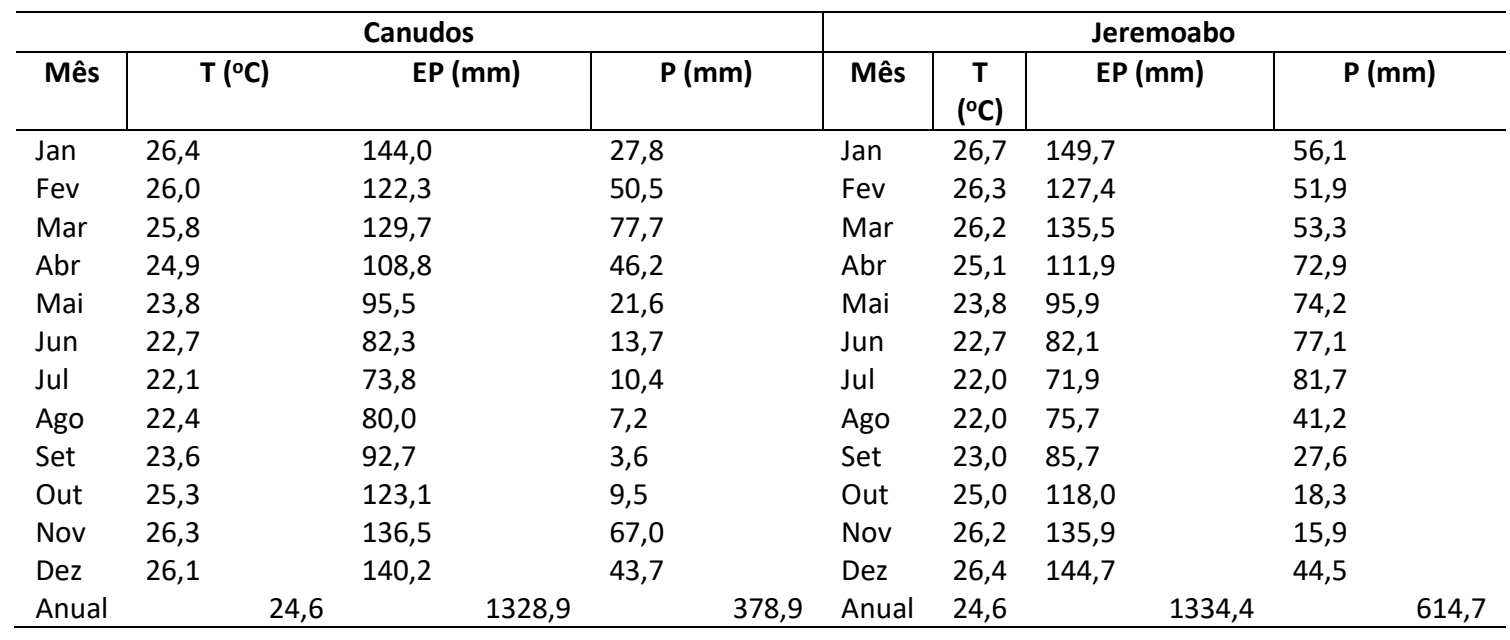

T: temperatura; EP: Evapotranspiração potencial; P precipitação

Em Jeremoabo, a temperatura média anual é de 24,6 으, a evapotranspiração potencial de $1.334,3 \mathrm{~mm}$ (SEI, 1999). Nele a quantidade de chuvas é um pouco superior em relação à Canudos, com um total em torno de $614,7 \mathrm{~mm}$ anuais (Tabela 1). Os maiores índices encontram-se nos meses de abril a julho, com um longo período de estiagem (SEI, 1999).

Cabe ressaltar que as características climáticas (temperatura, pluviosidade, evapotranspiração potencial, déficit hídrico etc.) são intrínsecas à dinâmica ambiental do trópico semiárido e, portanto, é importante que a população dos municípios de Canudos e Jeremoabo as considere no manejo da terra. Desta forma, é preciso utilizar espécies vegetais e animais aliadas às técnicas apropriadas e respeitar as condições edafoclimáticas da região, no intuito de potencializar a produção e evitar os processos de degradação e de desertificação.

Nos municípios de Canudos e Jeremoabo, as superfícies de maior extensão são constituídas por rochas sedimentares, em sua maioria formadas por arenitos, que totalizam $66,87 \%$, principalmente no centro e oeste (SIG-BA, 2003) (Figura 2). A geomorfologia é formada por duas unidades morfoestruturais: a bacia sedimentar Recôncavo-Tucano, constituída por formas de dissecação, aplanamentos embutidos e tabuleiros; e a depressão periférica e interplanáltica, formada por pedimentos funcionais ou retocados (SIG-BA, 2003). 
Figura 2. Canudos e Jeremoabo - Bahia: litologia

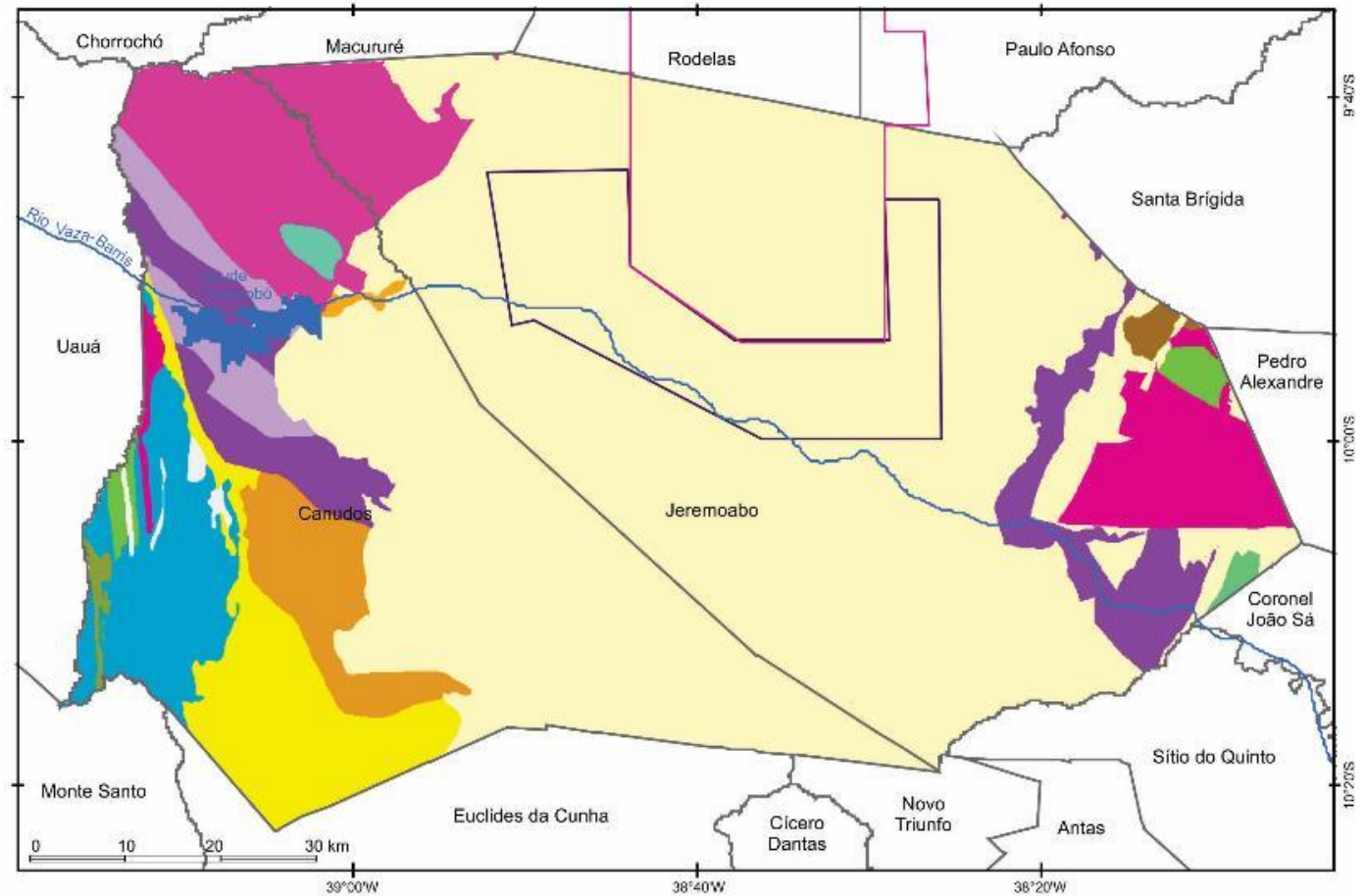

$\begin{array}{ll}\text { - Rio } & \text { Metagranito } \\ \text { - Limite politico e administrativo municipal } & \text { Sedimento aluvionar } \\ \text { - Estaçăo ecológica Raso da Catarina } & \text { Anfibolito } \\ \text { - APA Serra Branca } & \text { Areia } \\ \text { Lago } & \text { Arcoseo litico } \\ \text { Arenito } & \text { Gnaisse } \\ \text { Micaxisto } & \text { Calcarenito } \\ \text { Calcário } & \text { Metabásica } \\ \text { Granito } & \text { Calcilulito } \\ \text { Filito } & \text { Monsogranito }\end{array}$

De acordo com os dados extraídos do modelo digital do terreno (MDT), disponibilizado pelo programa Shuttle Radar Topography Mission (SRTM), da National Aeronautics and Space Administration (NASA), as altitudes variam entre $228 \mathrm{~m}$ e $766 \mathrm{~m}$, sendo que as áreas superiores formam os relevos de topos aplanados, bordas desniveladas com degraus e planos embutidos às encostas de formas predominantemente convexas, dissecadas nas rochas sedimentares arenosas e argilosas; e os relevos residuais, que se espalham por diferentes pontos (SIG-BA, 2003).

A declividade da área de estudo foi classificada em conformidade com as indicações de EMBRAPA (1979). Pelos dados extraídos do MDT, constatou-se que cerca de $45 \%$ das terras concernentes à área de estudo constituem de relevos ondulados, que possuem desníveis topográficos entre 4,50-11,3 (Figura 3). 0 suave-ondulado e forte-ondulado, em ordem, representam $26 \%$ e $23 \%$ dos municípios de Canudos e Jeremoabo (Figura 3). Pequenas porções municipais são compostas de relevos planos e montanhosos. Os 
menores índices de declividade formam os topos dos tabuleiros. As maiores declividades constituem as escarpas dos tabuleiros, dos relevos residuais e do vale do rio Vaza-Barris, as quais são consideradas, devido ao fator gravidade, as mais susceptíveis à erosão (Figura 3).

Figura 3. Canudos e Jeremoabo - Bahia: declividade

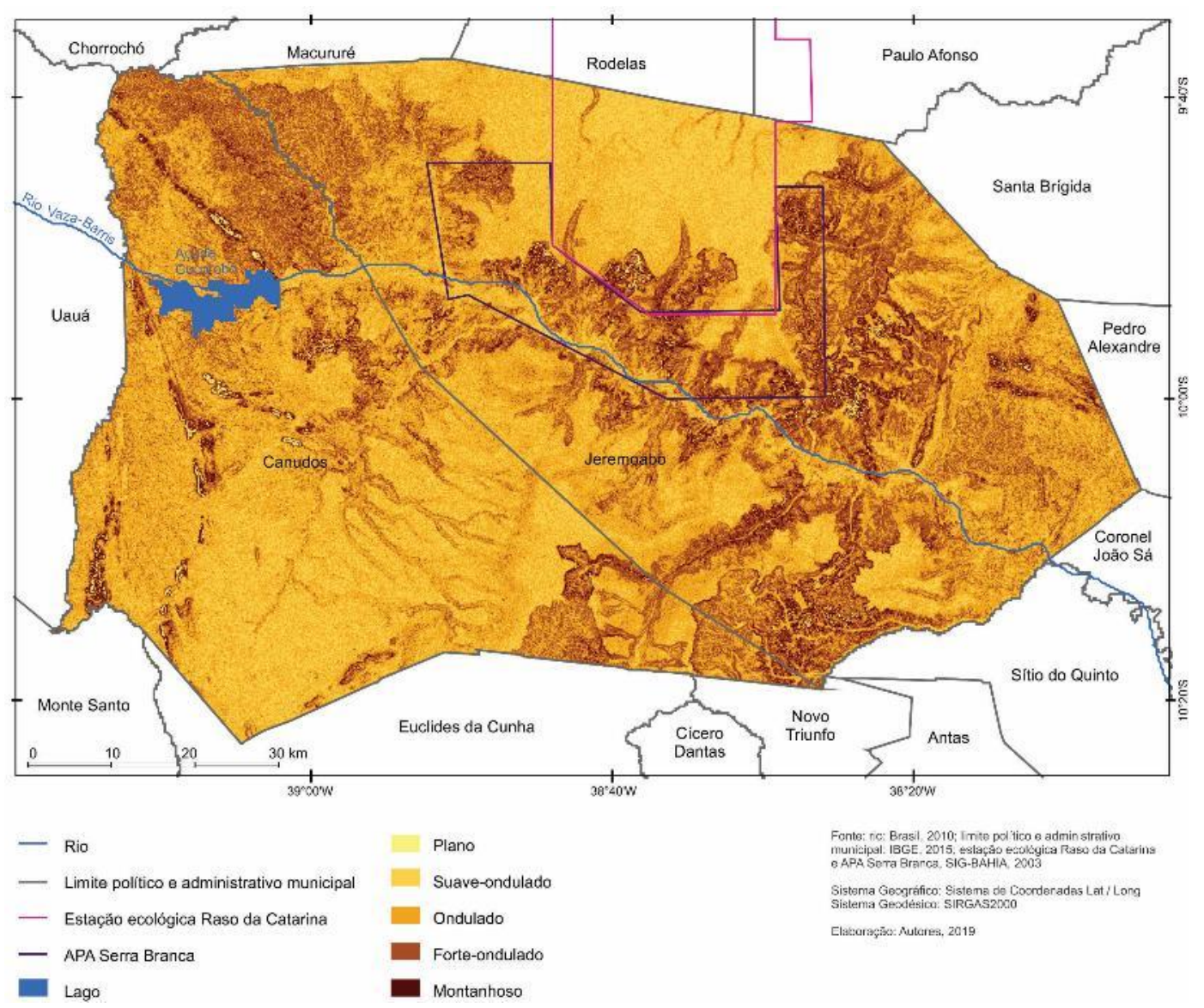

O perfil de curvatura relaciona-se ao caráter côncavo, convexo ou retilíneo do terreno, quando analisado em ângulo vertical. O padrão de distribuição das formas côncavas e convexas são semelhantes na área de estudo e obtém os respectivos valores: $38,20 \%$ e 30,81\%; apenas 22,94/\% do terreno tem distribuição retilínea.

O plano de curvatura refere-se ao caráter divergente, convergente dos fluxos, analisado em projeção horizontal. A análise desse atributo possibilita relacionar áreas decorrentes de acúmulo de umidade e a direção do fluxo da água superficial e subsuperficial na vertente. Na área de estudo, prevalece o plano retilíneo, com uma distribuição em $35 \%$ da área de estudo. As formas divergente e convergente possuem proporções semelhantes, em torno de $32 \%$.

Em razão das especificidades ambientais e do objetivo de estudo, analisou-se cinco classes de perfis topográficos de umidade e atestou-se que a classe média é aquela que possui maior amplitude espacial, 
equivalendo a $37,7 \%$ (Figura 4); junto com a classe baixa e muito baixa somam-se cerca de $70 \%$ da área de estudo. Assim, em função das características topográficas, existe pouca possibilidade de umidade no solo, pois o escoamento superficial hídrico é acentuado, com forte propensão de ocorrer processos erosivos.

Figura 4. Canudos e Jeremoabo - Bahia: índice topográfico de umidade

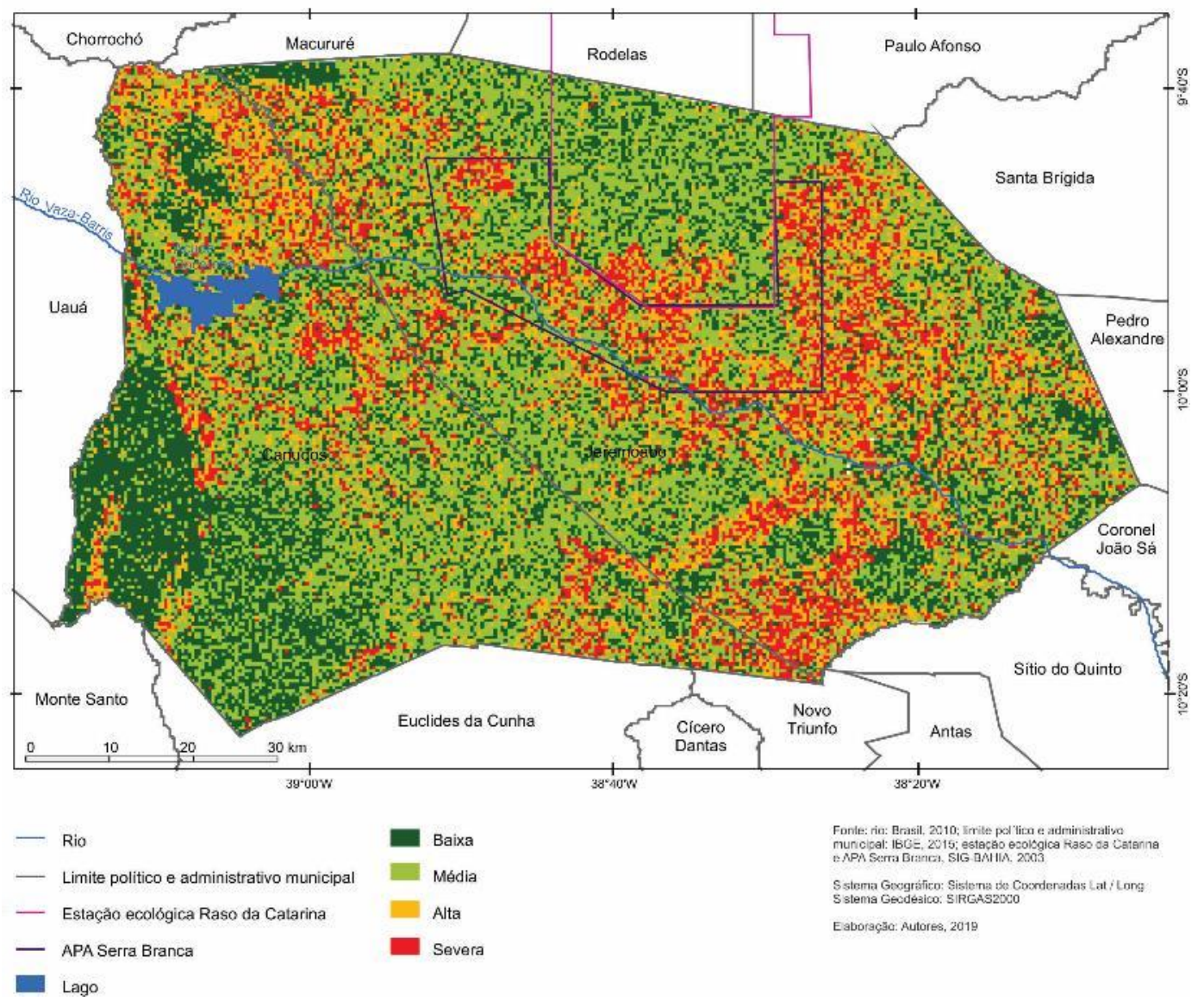

O conjunto de fatores naturais, como os climáticos, geológicos e geomorfológicos, associado às práticas excessivas e insustentáveis, contribuem para disseminação de solos rasos e com superfícies arenosas e/ou pedregosas, o que dificulta a retenção de água e nutrientes e elevam as possibilidades de ocorrência de erosão, como verificado em estudo de campo. O Neossolo quartzarênico e Neossolo litólico (Figura 5) distribuem, respectivamente, em 44,08\% e 35,10\% dos municípios, possuem capacidade agrícola de restrita a nula e são altamente suscetíveis aos processos de erosão eólica, pluvial e/ou fluvial. Encontram-se, também, os Argissolos, Cambissolo, Luvissolos, Planossolos e Vertissolos, utilizados, principalmente, para o cultivo em ciclos temporários (Figura 5). 
Figura 5. Canudos e Jeremoabo - Bahia: solos

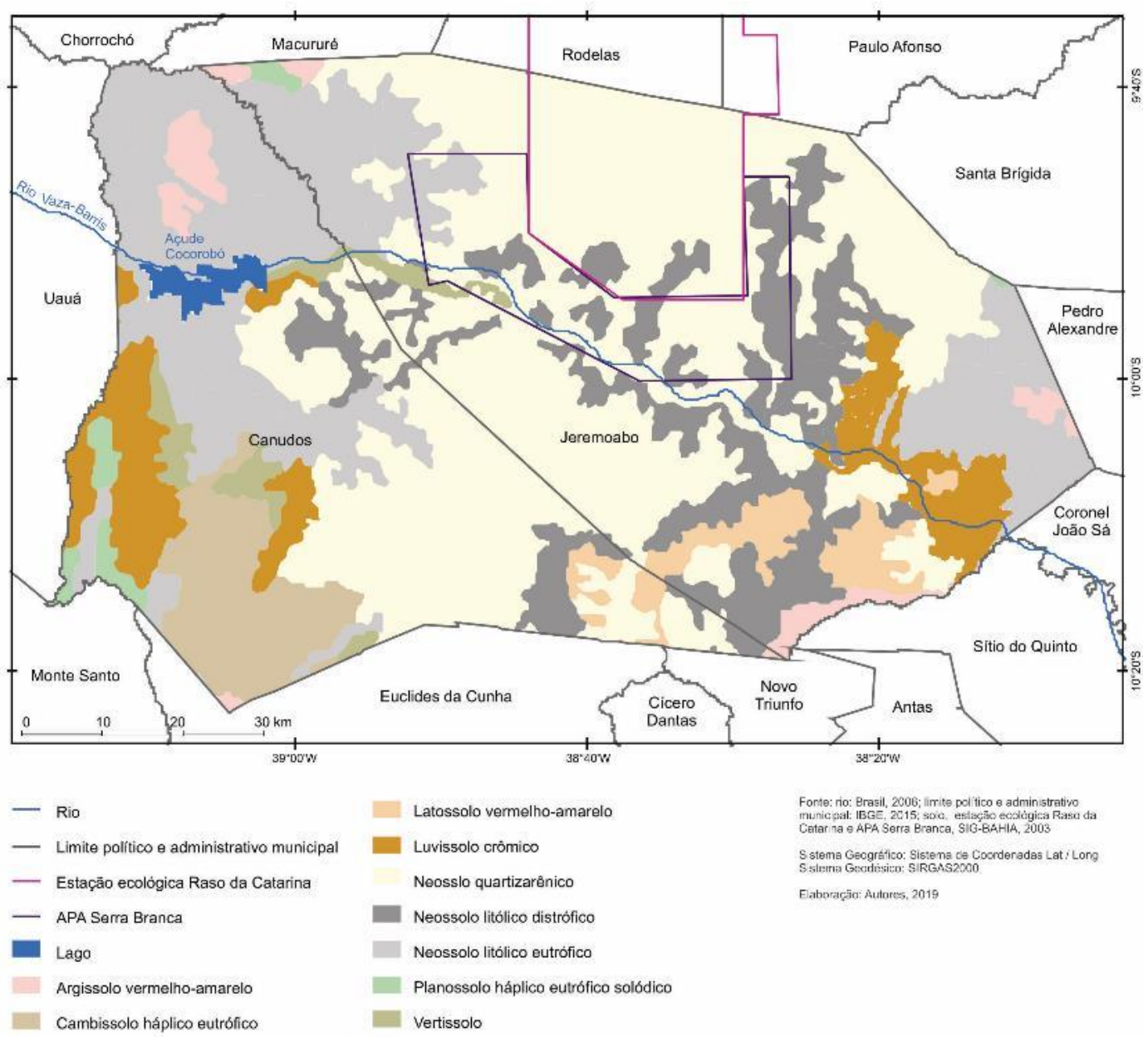

Uma das características marcantes da Área Susceptível à Desertificação é a presença de diversas tipologias de vegetação do bioma caatinga (NASCIMENTO, 2015). Elas são constituídas, majoritariamente, por espécies caducifólias, espinhentas, de portes arbóreo e arbustivo, aspectos rústicos e adaptadas às estiagens pluviométricas prolongadas. Na paisagem, destaca-se a caatinga arbórea-arbustiva, distribuindo-se em $54,03 \%$, sobretudo no centro da área de estudo (Figura 6). 
Figura 6. Canudos e Jeremoabo - Bahia: uso e cobertura da terra

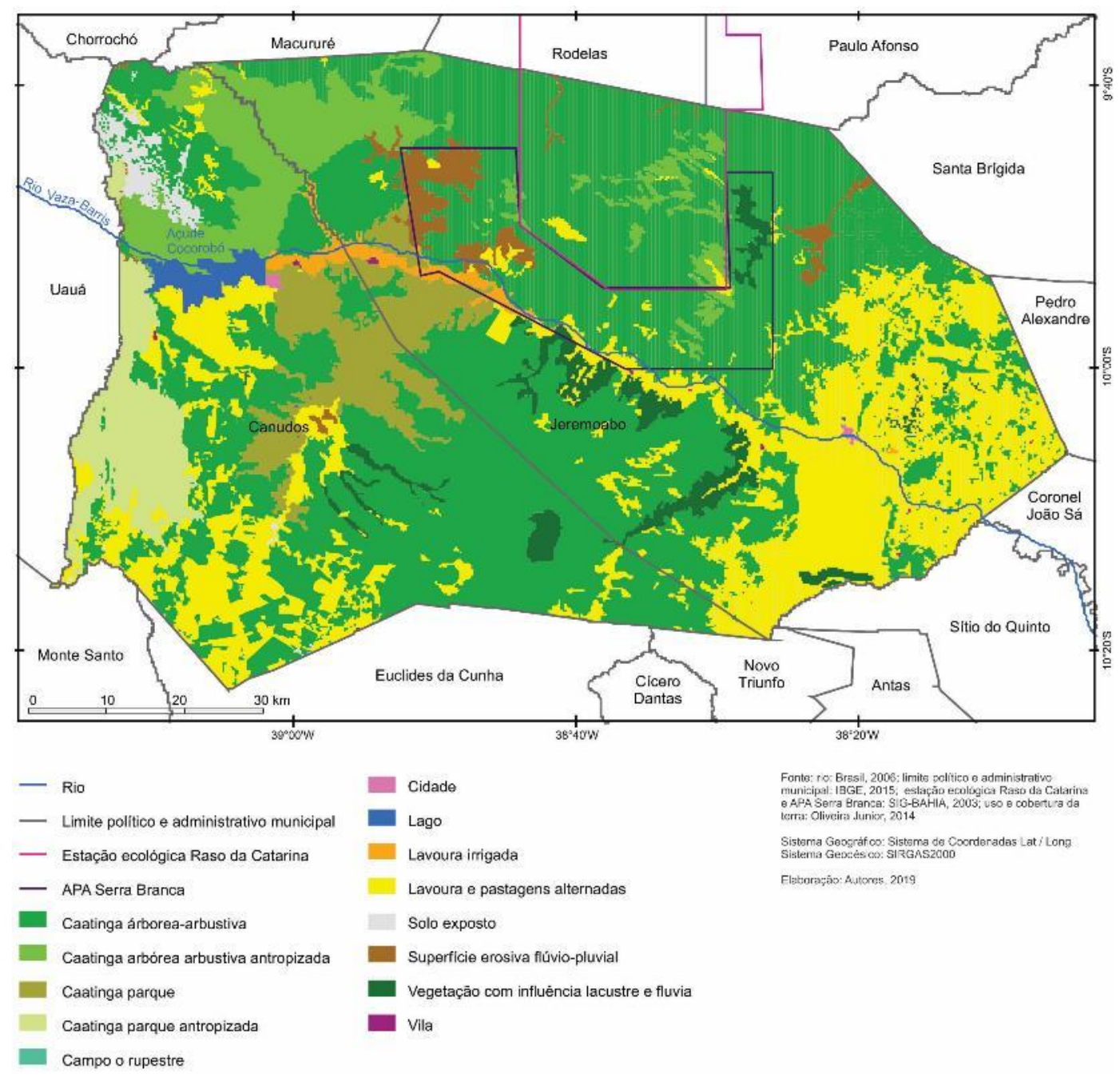

As atividades agropecuárias têm fragmentado a vegetação no leste e oeste dos municípios, recobrindo o solo com lavoura e pastagens alternadas (Figura 6). Algumas feições ambientais estão atreladas a deterioração ambiental, como o solo exposto e superfície erosiva flúvio-pluvial, que, em ordem, se distribui aproximadamente em $1 \%$ e 1,9\% (Figura 6). A substituição da vegetação natural para a ocorrência da agricultura e pecuária amplia as áreas de solo exposto. Em várias áreas, devido ao estrato e porte vegetativo, a biomassa não estabelece grande proteção aos solos às intempéries e os sujeitam aos processos e impactos da insolação constante e da erosão. 


\section{PROCEDIMENTOS METODOLÓGICOS}

A execução do estudo baseou-se, inicialmente, em uma revisão bibliográfica, para auxiliar na melhor definição do problema contendo observações, avaliações e discussões sobre os conceitos, causas e consequências referentes ao processo de desertificação, assim como susceptibilidade, modelagem ambiental e temas afins na literatura. Com isso, analisou-se referências para nortear a discussão sobre desertificação (HARE et al., 1992; LOPES et al., 2011; MAHYOU et al., 2016; NASCIMENTO, 2015; PEREZ-MARIN et al., 2012; SOUZA et al., 2010; SOUZA et al., 2015; UNCCD, 1997), modelagem de susceptibilidade à desertificação e lógica fuzzy (CREPANI et al., 2008; LOBÃO; VALE, 2013; MELENDEZ-PASTOR et al., 2010).

Junto à etapa da revisão da literatura, aconteceu uma análise cartográfica, para identificação de produtos pré-existentes importantes à pesquisa e ao mapeamento da suscetibilidade ambiental à desertificação. Com isso, construiu-se um banco de dados em formato de sistema de informação geográfica (SIG), com informações relacionados ao clima, relevo, litologia, solo, vegetação, uso da terra, de fontes secundárias, como aqueles disponibilizados pelo SIG-BA (2003). Esses dados foram fundamentais para iniciar o processo de modelagem de susceptibilidade ambiental à desertificação.

Elaborou-se mapas de variáveis do relevo, como declividade, plano de curvatura, perfil de curvatura e índice topográfico de umidade. Os dados foram extraídos do modelo digital de terreno (MDT), com resolução de $30 \mathrm{~m}$, a partir da aplicação de técnicas de geoprocessamento. Esses dados, conjuntamente aos mapas de litologia e solos, foram integrados no SIG da pesquisa, para análise da paisagem dos municípios e configuração de cenários ambientais. Para tanto, aplicou-se a lógica fuzzy, em que cada classe dos planos de informações compreendeu valores em um intervalo entre zero e um. Sabe-se que quanto mais próximo do valor um, maior a pertinência ao fenômeno que se quer evidenciar, por isso os limites das classes foram determinados em função da importância da modelagem de susceptibilidade.

No processo de análise ambiental e verificação dos produtos elaborados pelas técnicas de geoprocessamento, realizou-se estudos de campo, nos quais preencheu-se planilhas com informações ambientais e obteve-se as coordenadas geográficas no intuito de integrar os dados ao SIG da pesquisa.

\section{RESULTADOS E DISCUSSÃO}

O modelo ambiental de susceptibilidade ao processo de desertificação foi elaborado de acordo com as características da área de estudo e baseado, teoricamente, em Amaral e Ross (2009) e Crepani et al. (2008), ao abordar a proposta de unidades ecodinâmicas e vulnerabilidade à perda do solo, para indicar a evolução da paisagem e situar os estados ambientais. Os processos morfogenéticos são os pontos-chave para verificar 
a susceptibilidade à erosão, para tanto, integrou-se os dados referentes ao solo, relevo e rochas, conforme indicam os critérios sintetizados na figura 7.

Figura 7. Canudos e Jeremoabo - Bahia: planos de informações e níveis de pertencimento ao conjunto fuzzy de susceptibilidade ambiental ao processo de desertificação aplicados em ambiente de caatinga

\begin{tabular}{|c|c|c|}
\hline \multirow{15}{*}{ 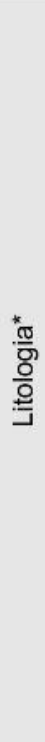 } & Arenito & 1,00 \\
\hline & Micaxisto & 0,50 \\
\hline & Calcário & 1,00 \\
\hline & Granito & 0,10 \\
\hline & Filito & 0,70 \\
\hline & Metagranito & 0,10 \\
\hline & Sedimento aluvionar & 1,00 \\
\hline & Anfibolito & 0,60 \\
\hline & Areia & 1,00 \\
\hline & Arcoseo lítico & 0,90 \\
\hline & Gnaisse & 0,43 \\
\hline & Calcarenito & 1,00 \\
\hline & Metabásica & 0,50 \\
\hline & Calcilulito & 1,00 \\
\hline & Monsogranito & 0,10 \\
\hline
\end{tabular}

\begin{tabular}{|c|c|c|}
\hline \multirow{4}{*}{ 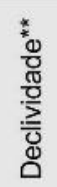 } & Plano & 0,50 \\
\hline & Suave-ondulado & 0,60 \\
\hline & Forte-ondulado & 0,80 \\
\hline & Montanhoso & 0,90 \\
\hline
\end{tabular}

\begin{tabular}{|c|c|c|}
\hline \multirow{5}{*}{ 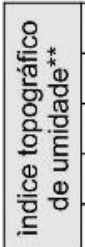 } & Muito-baixo & 0,30 \\
\hline & Baixo & 0,50 \\
\hline & Médio & 0,70 \\
\hline & Alto & 0,90 \\
\hline & Muito alto & 0,90 \\
\hline
\end{tabular}
"Niveis de pertencimento ao conjunto fuzzy baseado em Crepani (2007) dados em campo

\begin{tabular}{|c|c|c|}
\hline \multirow{3}{*}{ 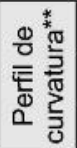 } & Convexo & 0,10 \\
\hline & Côncavo & 1,00 \\
\hline & Retilíneo & 0,60 \\
\hline
\end{tabular}

Fonte: Autores, 2019

\begin{tabular}{|c|c|c|}
\hline \multirow{9}{*}{ 응 } & Argissolo vermelho-amarelo & 0,50 \\
\hline & Cambissolo háplico eutrófico & 0,75 \\
\hline & Latossolo vermelho-amarelo & 0,01 \\
\hline & Luvissolo crômico & 0,50 \\
\hline & Neossolo quartzarêncio & 1,00 \\
\hline & Neossolo litólico distrófico & 1,00 \\
\hline & Neossolo litólico eutrófico & 1,00 \\
\hline & Planossolo háplico eutrófico & 0,50 \\
\hline & Vertissolo & 1,00 \\
\hline \multirow{3}{*}{ 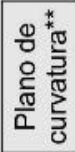 } & Divergente & 0,40 \\
\hline & Retilineo & 0,60 \\
\hline & Convergente & 0,90 \\
\hline
\end{tabular}

O modelo de susceptibilidade foi verificado com dados e informações obtidos em campo, numa busca de aproximá-lo à realidade ambiental em função das características ambientais encontradas nos municípios de Canudos e Jeremoabo. Por isso, aplicou-se a lógica fuzzy e o operador gamma com expoente 7, para evitar a configuração de cenários otimistas e pessimistas. 0 mapa resultante pode ser observado na figura 8.

Na modelagem (Figura 8), observou-se o predomínio das classes de menores índices de susceptibilidade, pois elas representam, juntas, $71 \%$ da área de estudo. A classe susceptibilidade alta correspondeu a $15 \%$ e a susceptibilidade severa a $13 \%$. São áreas onde encontram-se os níveis acentuados de fragilidade natural em relação à erosão, sem considerar as interferências humanas no processo de apropriação e uso das terras, como da agropecuária, mineração e extração vegetal. 
Figura 8. Canudos e Jeremoabo - Bahia: suscetibilidade ambiental à desertificação

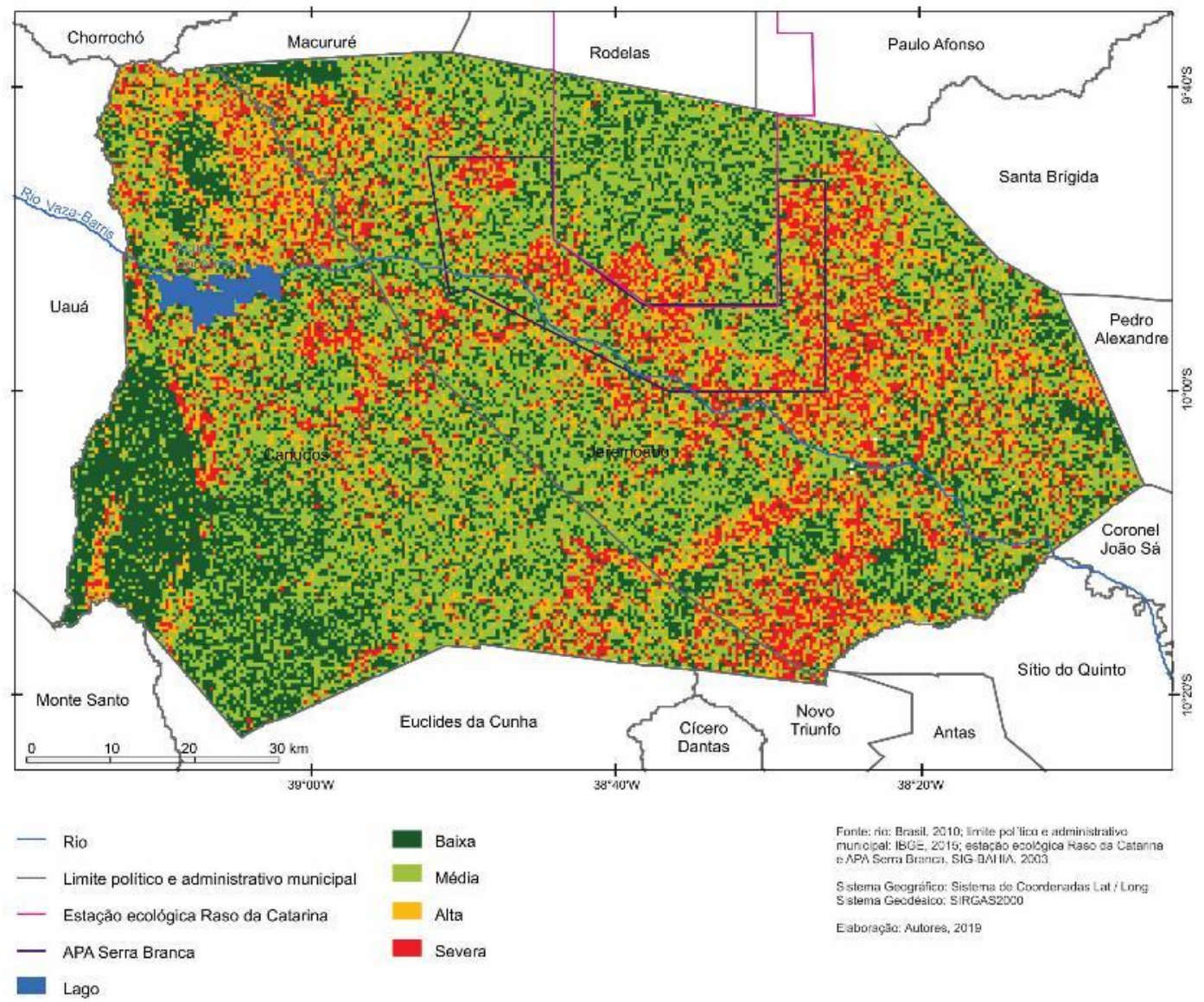

Elas se desenvolvem comumente em relevos ondulados, forte-ondulados e montanhosos, em função de serem mais propícios aos processos de erosão laminar, bem como em ambientes de médio-baixo e baixo índice topográfico de umidade, em razão das águas pluviais escoarem com facilidade e favorecerem os processos de erosão (Figura 9). Isso demonstra que as possibilidades de estabilidade ambiental são maiores onde há uma propensão a alta umidade do solo devido aos elementos topográficos.

Em relação ao plano e perfil de curvatura, as classes susceptibilidade alta e severa encontram-se, predominantemente, em relevos retilíneos e côncavos, devido às maiores possibilidades de ocorrência dos processos erosivos. Nos ambientes em que possuem arenitos, calcário e micaxisto distribuem-se, comumente, as classes de maiores índices de susceptibilidade à erosão, pois as referidas litologias são muitos frágeis à desagregação mecânica. 
Figura 9. Processos erosivos decorrentes em áreas de alta susceptibilidade à erosão em ambientes da caatinga - municípios de Canudos e Jeremoabo. A) Os processos de formação de ravinas e de erosão laminar em Neossolo litólico demarcam paisagens com superfícies pedológicas pedregosas; B) Em áreas de declividade ondulada, índice de topográfico de umidade baixo e ocorrência de Luvissolo desenvolvem ravinas e erosão laminar, com exposição das raízes dos arbustos espaçados; C) Nos ambientes de declividade suave-ondulada, índice topográfico de umidade baixo, plano de curvatura convergente e com o predomínio de Neossolos quartzarênicos, as chuvas de enxurrada esculpem, comumente, ravinas e voçorocas. Fonte: Autores, 2019
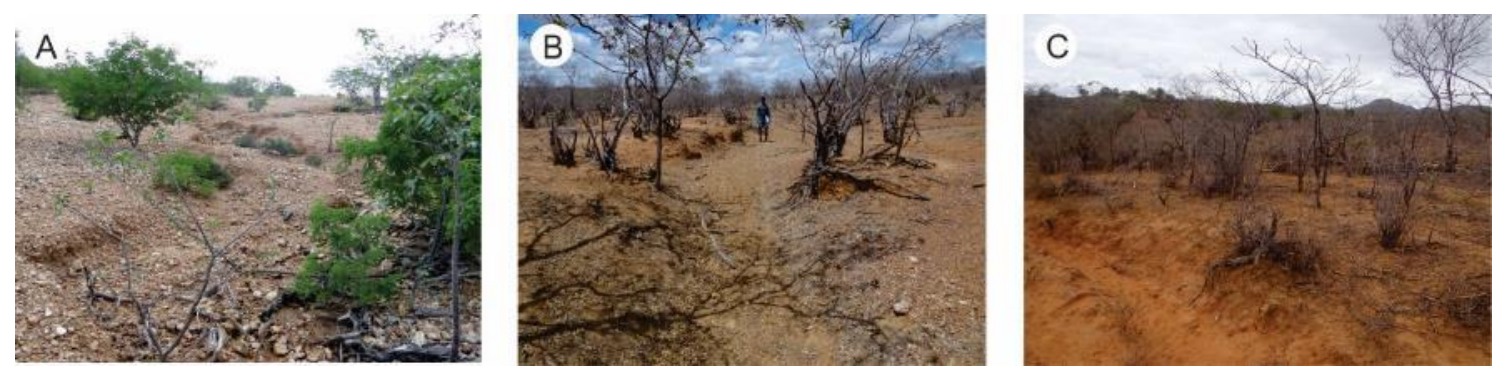

A susceptibilidade severa aparece em mais de $10 \%$ das terras de Canudos e $16 \%$ de Jeremoabo. Nos municípios, destaca-se a susceptibilidade média, que é superior a 40\%. Cerca de $1.000 \mathrm{~km}^{2}$ de ocorrência de Neossolos é qualificada como susceptibilidade severa, valor aproximado ao de susceptibilidade alta. Isso expressa a amplitude dos índices superiores de susceptibilidade ambiental à erosão associados aos referidos solos.

Os dados citados colocam em evidência a necessidade de realizar um planejamento eficaz de uso da terra, no intuito de evitar processos de erosão, que estão fortemente ligados à degradação ambiental das terras secas. Isso indica a necessidade de práticas conservacionistas, no tocante de evitar ações que desencadeiem a desertificação no bioma caatinga. A figura 10 demonstra as principais causas da degradação que conduzem à desertificação num ambiente de caatinga e, em particular, nos municípios em estudo.

Figura 10. Relação uso e erosão em ambiente de caatinga: uma abordagem em Canudos e Jeremoabo - Bahia. Fonte: Autores, 2019

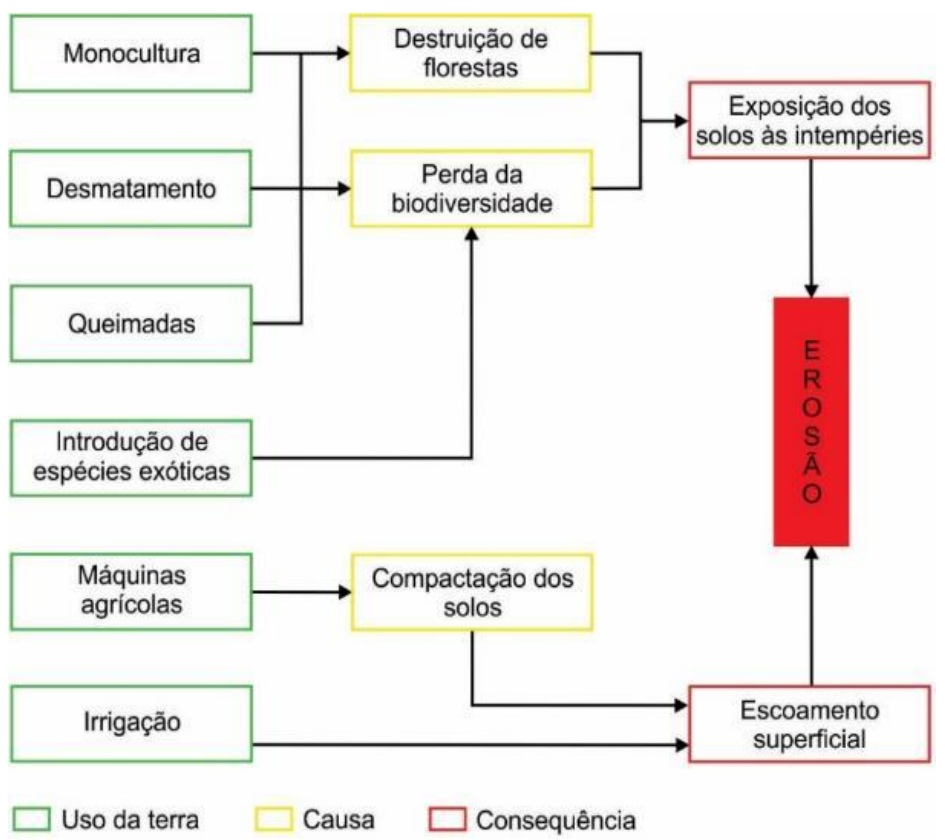


No bioma caatinga, algumas atividades listam os fatores de pressão ambiental que favorecem a intensificação dos processos erosivos, como as encontradas nos municípios de Canudos e Jeremoabo. A agropecuária situa-se no cerne das causas da desertificação, o que mostra um olhar preocupado para o desenvolvimento da agricultura, sobretudo no processo de apropriação dos recursos florestais da caatinga e sobre os solos mais susceptíveis à desertificação, como os Neossolos.

No contexto do desenvolvimento de atividades agrícolas, a principal causa da desertificação é o desmatamento, por expor os solos às intempéries climáticas, instalar e/ou potencializar os processos erosivos e diminuir a biodiversidade, como pode ser observado nas figuras 9 e 10. Por isso, é importante o manejo dos solos nas condições de alta e severa susceptibilidade à desertificação nos municípios de Canudos e Jeremoabo.

Com a modernização agrícola, a monocultura ou cultivo isolado (produção de apenas uma espécie em uma determinada área) ganhou bastante destaque. A produção de um ecossistema artificial exige constante intervenção humana, pois os fatores de produção da agricultura moderna exigem constantes modificações para ter resultados produtivos altos (ZIMMERMANN, 2009). Para aumentar a produtividade e a qualidade dos produtos, as técnicas empregadas para o desencadeamento do monocultivo induzem a desencadear os fatores da desertificação, como a apropriação de extensas áreas e do patrimônio ambiental, que acarretam no desmatamento da vegetação da caatinga, perda da biodiversidade animal, vegetal e diminuição da proteção natural contra pragas. Tudo isso contribui para a configuração de cenários propícios às doenças e pragas, torna esse modelo de produção cada vez mais submisso ao uso de agrotóxicos e cria um ciclo vicioso. Essas práticas devem ser evitadas prioritariamente nas áreas de susceptibilidade alta e severa, pois são causas potenciais para desencadear a erosão acelerada, como é o caso dos ambientes declivosos no vale do rio VazaBarris, onde é realizado a monocultura com práticas agrícolas irrigadas.

A desertificação tende a começar com o desmatamento, que gera o desaparecimento das espécies vegetais (SILVA; PACHÊCO, 2016; VIEIRA et al., 2017). A principal consequência constitui na perda da biodiversidade, com a destruição das florestas e resultam em solo exposto (Figura 6). O habitat natural de muitas espécies torna-se escasso ou inexistente, decorre na morte de muitos animais e amplia o risco de extinção de espécies, sobretudo as endêmicas. Há, ainda, impactos indiretos, como no comprometimento da qualidade da água, erosão hídrica e eólica sobre os ambientes mais susceptíveis, como os especificados na figura 8. Outro fator de deterioração é a introdução de espécies exóticas na área de estudo, à exemplo da algaroba (Prosopis juliflora), pois ocupa grandes extensões de terras e ameaça a biodiversidade, devido à facilidade de dispersão e adaptação às condições edafoclimáticas, o que se deve ter uma atenção redobrada no vale do rio Vaza-Barris, onde ela se espalha intensamente.

A erosão é a mais grave das causas de degradação dos solos por sua dificuldade de reversão, visto causar um empobrecimento dos nutrientes, uma vez que a camada superficial do solo é a mais nutritiva; decorre na 
redução na profundidade do solum, diminuição da capacidade de retenção hídrica e de nutrientes. O processo leva a um declínio na fertilidade do solo e no crescimento e na produtividade das plantas; o solo recebe menos matéria orgânica e o húmus mineraliza-se mais rapidamente, por causa dos efeitos das elevadas temperaturas. Os elementos citados têm ocasionado a desertificação, onde a ausência de vida prevalece, o que demonstra a necessidade de atentar-se para os resultados da modelagem de susceptibilidade à desertificação em Canudos e Jeremoabo (Figura 8).

Com a modernização da agricultura, a utilização de maquinários agrícolas se alastrou, decorrendo na modificação acentuada da estrutura física do solo, como a ocorrência da compactação. Os pesos das máquinas e dos equipamentos têm aumentado, porém o tamanho e a largura do pneu não acompanharam essa evolução. Os pneus usualmente utilizados nos tratores e colhedoras comercializadas no Brasil possuem a parte lateral rígida, sendo chamados de pneus de banda diagonal. Essa rigidez impede que o pneu se molde ao solo acordado com as irregularidades do terreno e, por isso, a sua área de contato fica reduzida, aumentando a pressão na superfície do solo (JODOSKI et al., 2016).

$\mathrm{Na}$ área de estudo, os agricultores têm utilizado de máquinas agrícolas para preparar a terra no processo de cultivo em diferentes escalas, tanto nas pequenas e grandes propriedades. A realidade mencionada é verificada em ambientes onde encontram-se níveis acentuados de susceptibilidade ambiental à erosão e constituem em fatores de uso que ampliam os processos erosivos na área de estudo, como os encontrados ao sul do lago de Cocorobó, localizado no município de Canudos, e em toda extensão do vale do rio Vaza-Barris. Ainda, em decorrência da compactação, tem-se um aumento da resistência do solo e há uma dificuldade do crescimento radicular, redução da porosidade, da permeabilidade hídrica, disponibilidade de nutrientes, diminuição da circulação de ar e erosão.

Os resultados da modelagem apontam para especificar as áreas de alta e severa susceptibilidade ambiental e, associada ao mapa de uso e cobertura da terra (Figura 8), demonstram a importância da vegetação para a manutenção do equilíbrio ambiental. Em áreas onde vegetação da caatinga é conservada, observa-se a ausência de processos erosivos acelerados, mesmo sendo constituídas de solos friáveis, como os Neossolos, declividades onduladas a forte-ondulada, índice topográfico de umidade baixo, perfil de curvatura côncavo e plano de curvatura convergente (Figura 11).

Isso indica a importância da cobertura vegetal para a manutenção de estados de equilíbrio ambiental e evitar os fatores que desencadeiam o processo de desertificação. Sobre os frágeis solos da catinga recobertos por vegetação, a insolação é menor, a evaporação da água do solo é diminuída, os impactos das chuvas de enxurradas são inferiores, evita-se o desencadeamento da erosão acelerada e possibilita configurar os mecanismos de crescimento vegetativo e conservação ambiental. 
Figura 11. Vegetação conservada em áreas de alta e severa susceptibilidade ambiental - município de Canudos e Jeremoabo. A) Caatinga arbórea-arbustiva conservada sobre os Cambissolos desenvolvidos em relevos com perfil de curvatura côncavo, plano de curvatura convergente, índice topográfico de umidade médio. B) A existência de Neosolo litólico, em relevos com declividade forteondulada, perfil de curvatura côncavo e plano de curvatura divergente configuram estados de severa susceptibilidade ambiental; a presença de vegetação possibilita a conservação ambiental. C) A implantação da Reserva Ecológica Raso da Catarina possibilitou a regeneração da vegetação e conservação ambiental em áreas de severa susceptibilidade. Fonte: Autores, 2019
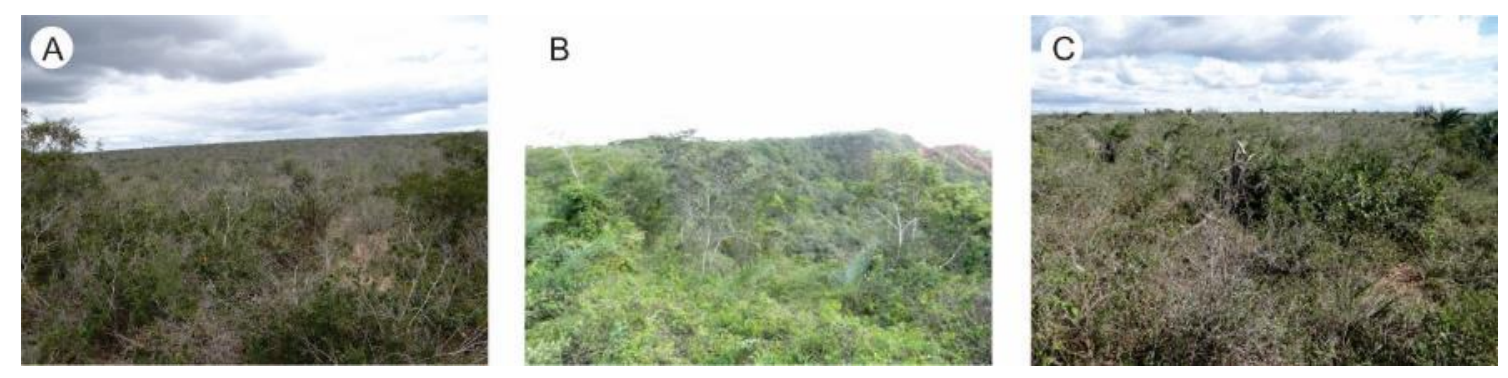

Essa situação foi encontrada, por exemplo, na Estação Ecológica do Raso da Catarina, no município de Jeremoabo-BA, onde as características são de alta e severa susceptibilidade ambiental. Assim, atesta-se a importância das unidades de conservação como meio de reverter e combater as causas do processo de desertificação, como as relacionadas à erosão acelerada.

\section{CONSIDERAÇÕES FINAIS}

Por meio dos estudos realizados nesta pesquisa, observou-se a importância do geoprocessamento para a elaboração de dados e configuração de informações ambientais no contexto da desertificação. A formação de um banco de dados SIG possibilitou a análise da paisagem da área de estudo, a partir de dados secundários e a confecção de dados primários com rigor científico.

A lógica empregada e o estabelecimento dos níveis de pertencimento ao conjunto fuzzy indicaram a correspondência entre o modelo de susceptibilidade ambiental à desertificação e a realidade de campo, com a especificação das áreas com forte propensão a ocorrência da degradação das terras secas. A suscetibilidade severa se estende por $13 \%$ da área de estudo, onde são encontrados relevos declivosos, retilíneos, convexos, de médio-baixo e baixo índice topográfico de umidade. Em geral, nos Neossolos litólicos, Neossolo quartzarênico e Vertissolos.

A severidade da susceptibilidade é mais comum no centro, leste o noroeste da área de estudo. No centro, a conservação da caatinga arbórea-arbustiva é de importância para impedir a ocorrência da erosão acelerada e manter o estado de equilíbrio ambiental; o que se contrapõe com o leste e noroeste. As práticas empreendidas no uso da terra têm gerado deterioração ambiental, visíveis na intensificação dos processos erosivas, com o desencadeamento de sulcos, ravinas e voçorocas. 
Os estudos sobre as terras secas evidenciam a práticas humanas como o principal fator da desertificação, decorrente em um ambiente demarcado pela fragilidade ambiental. A diminuição da produtividade agrícola e da pecuária são impactos recorrentes em áreas onde a problemática se instala.

\section{AGRADECIMENTOS}

À Fundação de Amparo à Pesquisa da Bahia (FAPESB) pela concessão de bolsa ao segundo autor na modalidade Doutorado - Cotas.

\section{REFERÊNCIAS}

ABDI, O. A.; GLOVER, E. K.; LUUKKANEN, O. Causes and impacts of land degradation and desertification: case study of the Sudan. International Journal of Agriculture and Forestry, [s.I], v. 3, n. 2, p. 40-51, 2013.

AMARAL, R.; ROSS, J. L. S. As unidades ecodinâmicas na análise da fragilidade ambiental do Parque Estadual do Morro do Diabo e Entorno, Teodoro Sampaio/SP. Geousp, São Paulo, n. 26, p. 59-78, 2009.

ARAGÃO, R; ALMEIDA, J. A. P.; FIGUEIREDO, E. E.; SRINIVASAN, V. S. Mapeamento do potencial de erosão laminar na Bacia do Rio Japaratuba, SE, via SIG. Revista Brasileira de Engenharia Agrícola e Ambiental, Campina Grande, v. 15, n. 7, p. 731-740, 2011.

ARAÚJO, J. A.; SOUZA, R. F. Abordagens sobre o processo de desertificação: uma revisão das evidências no Rio Grande do Norte. Geosul, Florianopólis, v. 32, n. 65, p. 122-143, 2017.

BORTOLUZZI, E. C.; RHEINHEIMER, D. S.; GONÇALVES, C. S.; PELLEGRINI, J. B. R. ANELLA, R.; COPETTI, A. C. C. Contaminação de águas superficiais por agrotóxicos em função do uso do solo numa microbacia hidrográfica de Agudo, RS. Revista Brasileira de Engenharia Agrícola e Ambiental, Campina Grande, v. 10, n. 4, p. 881-887, 2006.

COSTA, T. C. C.; OLIVEIRA, M. A. J.; ACCIOLY, L. J. O. SILVA, F. H. B. B. Análise da degradação da caatinga no núcleo de desertificação do Seridó (RN/PB). Revista Brasileira de Engenharia Agrícola e Ambiental, Campina Grande, v.13, p. 961-974, 2009.

CREPANI, E. MEDEIROS, J. S.; PALMEIRA, A. F.; SILVA, E. F. Zoneamento ecológico-econômico. In: FLORENZANO, T. G. (Org.) Geomorfologia: conceitos e tecnologias atuais. São Paulo: Oficina de Textos, 2008.

EMPRESA BRASILEIRA DE PESQUISA AGROPECUÁRIA - EMBRAPA. Serviço Nacional de levantamento e conservação de solos. Rio de Janeiro: EMBRAPA, 1979.

Sistema brasileiro de classificação de solos. 2. ed. Rio de Janeiro: EMBRAPA-SPI, 2006.

FENG, Q.; MA, H.; JIANG, X.; WANG, X.; CAO, H. What has caused desertification in China? Scientific Reports, [s.I], v. 5, n. 15998, p. 18, 2015.

GUERRA, A. J. T.; FULLEN, M. A.; JORGE, M. C. O.; ALEXANDRE, S. T. Soil erosion and conservation in Brazil. Anuário do Instituto de Geociências, Rio de Janeiro, v. 37, n. 1, p. 81-91, 2014.

HAMZA, M. A. WALTER, A. Soil compaction in cropping systems: a review of the nature, causes and possible solutions. Soil and Tillage Research, [s.I], v. 82, n. 2, p. 121-145, 2005.

HARE, F. K et al. Desertificação: causas e consequências. Lisboa: Fundação Calouste Gulbenkian, 1992.

JODOSKI, G. S.; PINHEIRO, T. D.; SANTOS JÚNIOR, P. S.; RODRIGUES, F. R. M. Influência das características do pneu na performance do trator. Brazilian Journal of Applied Technology for Agricultural Science, Guarapuava, v. 9, n. 2, p. 115-120, 2016.

KATYAL, J. C.; VLEK, P. L. G. Desertification: concept, causes and amelioration. Bonn: Center for Development Research, 2000.

LEE, J. A.; GILL, T. E. Multiple causes of wind erosion in the Dust Bowl. Aeolian Research, n. 19, p. 15-36, 2015 
LOBÃO, J. S. B.; VALE, R. M. C. Lógica fuzzy na modelagem da desertificação no estado da Bahia. Geografia, Rio Claro, v. 38, n. 1, p. 123-140, 2013.

LOPES, L. S. O.; SANTOS, R. W. P.; MIGUEL FILHO, M. A. Núcleo de desertificação de Gilbués (PI): causas e intervenções. Geografia, Londrina, v. 20, n. 2, 53-66, 2011.

MAHYOU, H.; TYCHON, B.; BALAGHI, R.; LOUHAICH, M.; MIMOUNI, J. A knowledge-based approach for mapping land degradation in the arid rangelands of north Africa. Land degradation \& development, [s.I], v. 27, p. 1574-1585, 2016.

MELENDEZ-PASTOR, I.; SOLA, P. C.; NAVARRO-PEDREÑO, J.; GÓMEZ, I. Evaluación de la vulnerabilidad a la degradación por erosión en suelos mediante un modelo de lógica borrosa. Revista de Ciências Agrárias, Lisboa, v.33, n.1 Lisboa, p. 172-181, 2010.

NASCIMENTO, F. R. Os semiáridos e a desertificação no Brasil. REDE, Fortaleza, v. 9, n. 2, p. 7-26, 2015.

OLIVEIRA JUNIOR, O.; LOBÃO, J. S. B.; SILVA, B. C. N.; PEREIRA, A. J. Indicadores socioeconômicos de desertificação: análise da produção agropecuária no polo regional de Jeremoabo - Bahia. Geonordeste, São Cristóvão, v. 29, n. 1, p. 23-42, 2018.

PEREZ-MARIN, A. M.; CAVALCANTE, A. M. B.; MEDEIROS, S. S.; TINÔCO, L. B. M. SALCEDO, I. H. Núcleos de desertificação no semiárido brasileiro: ocorrência natural ou antrópica? Parc. Estrat, Brasília (DF), v. 17, n. 34, p. 87-106, 2012.

QIAN, T.; TSUNEKAWA, A.; MASUNAGA, T.; WANG, T. Analysis of the spatial variation of soil salinity and its causal factors in China's Minqin Oasis. Mathematical Problems in Engineering, Cairu, v. 2017, p. 1-9, 2017.

RÊGO, A. H. Os sertões e os desertos: o combate à desertificação. Brasília (DF): FUNAG, 2012.

SALOMÃO, F. X. T. Controle e prevenção dos processos erosivos. In: GUERRA, A. J. T; SILVA, A. S.; BOTELHO R. G. M. (org.). Erosão e conservação dos solos: conceitos, temas e aplicações. 8.ed. Rio de Janeiro: Bertrand Brasil, 2012. cap. 7. p. 229-267.

SANTOS, G. G.; GRIEBELER, N. P.; OLIVEIRA, L. F. C. Chuvas intensas relacionadas à erosão hídrica. Revista Brasileira de Engenharia Agrícola e Ambiental, Campina Grande, v.14, n.2, p.115-123, 2010.

SHAH, A. N.; TANVEER, M.; SHAHZAD, B.; YANG, G.; FAHAD, S.; ALI, S.; BUKHARI, M. A.; TUNG, S. A.; HAFEEZ, A.; SOULIYANONH, B. Soil compaction effects on soil health and crop productivity: an overview. Environmental Science and Pollution Research, [s.I], v. 24, n. 11, p. 10056-10067, 2017.

SILVA, F. G. C. S.; PACHECO, J. S. Processo de desertificação: estudo de caso em Irauçuba-CE. Teccen, Vassouras, v. 9, n. 1, p. 47-51, 2016.

SISTEMA DE INFORMAÇÃO GEOREFERENCIADAS - SIG-BAHIA Sistema de informações sobre recursos hídricos - SIRH. Salvador: Superintendência de Recursos Hídricos, 2003. 2 CD - Rom.

SOUZA, B. I.; ARTIGAS, R. C. LIMA, E. R. V. Caatinga e desertificação. Mercator, Fortaleza, v. 14, n. 1, p. 131-150, 2015.

SOUZA, B. I.; SUERTEGARAY, D. M. A.; LIMA, E. R. V. Políticas públicas, uso do solo e desertificação nos Cariris Velhos (PB/Brasil). Scripta Nova, Barcelona, v. 14, n. 311, p. 1-14, 2010.

SUPERINTENDÊNCIA DE ESTUDOS ECONÔMICOS E SOCIAIS DA BAHIA (SEI). Balanço hídrico do estado da Bahia. Salvador: SEI, 1999.

UNITED NATIONS CONVENTION TO COMBAT DESERTIFICATION - UNCCD. Convenção das Nações Unidas de combate à desertificação nos países afetados por seca grave e/ou desertificação, particularmente na África. Brasília (DF): Ministério do Meio Ambiente, 1997.

VIEIRA, A. T.; MAGALHÃES, M. F.; SILVA, M. V. C. Uso da terra como facilitador da degradação ambiental no município de Santa Quitéria, Ceará. Revista Brasileira de Geografia Física, Recife, v. 10, n. 4, p. 1329-1345, 2017.

ZIMMERMANN, C. L. Monocultura e transgenia: impactos ambientais e insegurança alimentar. Veredas do Direito, Belo Horizonte, v. 6, n. 12, p. 79-100, 2009. 